\title{
Effect of Metformin on Serum Thyrotropin (Thyroid Stimulating Hormone) Levels in Hypothyroid Patients on Stable and Adequate Levothyroxine Doses with Diabetes or Pre- Diabetes
}

Anirban Sinha ${ }^{1 *}$, Kingshuk Bhattacharjee ${ }^{2}$, Pulakesh Sinha ${ }^{3}$, Aditya Verma ${ }^{3}$, and Ashesh Halder ${ }^{3}$

${ }^{1}$ Department of Endocrinology, Medical College, 88, college street.kol-73, Kolkata

${ }^{2}$ Assistant Manager, Medical Services, Biocon Limited, Bangalore

${ }_{3}^{3}$ Junior Resident, Department of General Medicine, Medical College, Kolkata

Received: August 22, 2016; Accepted: September 30, 2016; Published: October 03, 2016

*Corresponding author: Anirban Sinha, Assistant Professor, Department of Endocrinology, Medical College, 88, college street.kol-73, Kolkata,

E-mail:anirban.doc@gmail.com

\begin{abstract}
Aims: To assess the effect of metformin on serum thyrotropin (thyroid stimulating hormone) levels in hypothyroid patients on stable and adequate levothyroxine doses with diabetes or prediabetes.

Settings and Design: Prospective clinic based study

Methods and Material: Total 80 patients age more than 18 years, diagnosed hypothyroid, adequate and stable LT4 replacement therapy, type 2 diabetes or prediabetes, only on metformin along with diet and life style modification for blood sugar control were studied over a period of 12 months. In control group, patients received adequate and stable supplementation of LT4 without metformin. Serum TSH values at baseline, after three months, six month and 12 months were analysed.
\end{abstract}

Statistical analysis used: Unpaired t-test to find significant difference in the baseline and follow-up study parameters namely LT4 and TSH between two groups. Repeated measure ANOVA was used to observe the within group differences for the changes in LT4 and TSH.

Results: In study group, after three, six \& 12 months of on metformin, mean TSH was significantly lower than basal TSH, p < 0.0001 for all time points. Mean free T4 (FT4) level changes were nonsignificant in three month, but significantly increased after six \& 12 months of metformin administration, $\mathrm{p}=0.691, \mathrm{p}=0.007$, and $\mathrm{p}=0.001$ respectively) whereas non-significant changes in mean TSH and mean FT4 in control group.

Conclusions: Treatment with metformin is associated with significant reduction in the serum TSH levels. TSH reduction is not associated with reciprocal changes in FT4 at three months but at six months and 12 months and is associated with significant increase of FT4 in primary hypothyroidism patients on stable and adequate levothyroxine doses who were found to have diabetes or prediabetes.

Key-words: TSH, Metformin, hypothyroid, T2DM, Pre-diabetes

\section{Introduction}

Various epidemiological studies showed the coexistence of diabetes and hypothyroidism. Researchers have discovered the TSH suppressing role of metformin in diabetic patients undergoing levothyroxine (LT4) treatment and excluded the biological interference of metformin with TSH assay, increased LT4 absorption from gastrointestinal tract or any influence of changes in body weight associated with metformin treatment. It was hypothesized that metformin may enhance the inhibitory modulation of thyroid hormones on central thyroid stimulating hormone secretion ${ }^{[1]}$. In obese, diabetic patients with primary hypothyroidism on thyroxine replacement treatment, shortterm metformin administration is associated with a significant fall in $\mathrm{TSH}^{[2]}$ This emerging finding might render this drug a useful adjunct to the treatment of patients with thyroid cancer and possible readjustment of LT4 doses and will open up new dimension of metformin use and enrich the field of medicine. ${ }^{[3]}$

In the present study, we aim to observe the impact of metformin on serum TSH levels in hypothyroid patients who are on stable and adequate LT4 and found to have diabetes or prediabetes. We also intend to compare the above mentioned group with hypothyroid patients who are on adequate and stable LT4 replacement therapy without diabetes or prediabetes. Although there are many similar studies published on this research problem, this is the first study from Indian subcontinent population.

\section{Subjects and Methods}

This prospective single-centred study was conducted on 40 cases and 40 controls randomly selected from the outpatient 
as well as inpatient section of medicine and endocrinology department, Medical College and Hospital, Kolkata satisfying the inclusion and exclusion criteria between February 2013 and January 2014. Type 2 diabetes or pre-diabetes adult patients of both sexes who were only on metformin alongwith diet and lifestyle modifications and with diagnosed hypothyroidism on adequate and stable L-T4 replacement therapy were included as cases. The control cohort comprised hypothyroid patients (age and sex matched) receiving adequate and stable supplementation of L-T4 without metformin. Patients with uncontrolled hypothyroidism or who were taking oral hypoglycemic agents (OHA) other than metformin or on insulin or on metformin and other OHA or on any hormonal supplementation or medication affecting thyroid function test like oral contraceptive pill etc. were excluded from the study. Laboratory assessments included fasting blood sugar, two hours post load glucose or Post prandial blood sugar, free T4 and TSH were measured and studied at baseline, at three months, at six months and at one year.

Descriptive statistical analysis was carried out in the present study. Results of continuous measurements were presented as mean \pm standard deviation (Min-Max) and results of categorical measurements were presented in Number (\%). Significance was assessed at the $5 \%$ level. Unpaired t-test to find significant difference in the baseline and follow-up study parameters namely LT4 and TSH between two groups. Repeated measure ANOVA was used to observe the within group differences for the changes in LT4 and TSH. SAS (Statistical Analysis System) version 9.2 for windows, SAS Institute Inc. Cary, NC, USA and SPSS (Statistical Package for Social Sciences) version 20.0 was used for the analysis of the data and Microsoft word and Excel were used to generate graphs and tables.

\section{Results}

The study group has two patients aged $<30$ years, 13 patients aged between 31-40years, 13 patients aged between $41-50$ years, nine patients aged between 51-60 years and three patients aged $>60$ years. The control group has three patients aged $<30$ years,14 patients aged between 31-40years, nine patients aged between 41-50 years, 12 patients aged between 51-60 years and two patients aged $>60$ years. Both the study group (metformin group) and the control group have 17 (17.5\%) male and $33(82.5 \%)$ female subjects. In study group $62.5 \%$ patients have BMI in between 18.5 - 24.9 (normal ),27.5\%patients have BMI in between $25-29.9$ (pre obese),10\%atients have BMI $\geq 30$ (obese).In control group $65 \%$ patients have BMI in between 18.5 - 24.9(normal ), 25\% patients have BMI in between 2529.9 (pre obese), $10 \%$ patients have BMI $\geq 30$ (obese). In the study group (metformin group) $60 \%$ have goitre and in control group (others) 65\% have goitre.

In the study group (case cohort) after three months of on metformin, mean TSH was significantly lower than basal TSH (basal TSH: $4.018 \pm 0.7207 \mathrm{microUI} / \mathrm{ml}$ vs. three months after metformin TSH: $3.72 \pm 0.6216 \mathrm{microUI} / \mathrm{ml}, \mathrm{P}<0.0001$ ). Mean FT4 level changes during metformin administration (basal FT4: $1.344 \pm 0.2514 \mathrm{ng} / \mathrm{dl}$, three months after metformin FT4:
$1.3405 \pm 0.2437 \mathrm{ng} / \mathrm{dl}, \mathrm{p}=0.691$, which is non-significant. After six months of on metformin, mean TSH was significantly lower than basal TSH (basal TSH: $4.018 \pm 0.7207 \mathrm{microUI} / \mathrm{ml}$ vs. six months after metformin TSH: $2.966 \pm 0.7194 \mathrm{microUI} / \mathrm{ml} ; \mathrm{P}<$ 0.0001). Mean FT4 level significantly increases during metformin administration (basal FT4: $1.344 \pm 0.2514 \mathrm{ng} / \mathrm{dl}$, six months after metformin FT4: $1.372 \pm 0.238 \mathrm{ng} / \mathrm{dl}$; $\mathrm{p}=0.007$ ). After 12 months of on metformin, mean TSH was significantly lower than basal TSH (basal TSH: $4.018 \pm 0.7207 \mathrm{microUI} / \mathrm{ml}$ vs. 12 months after metformin TSH: $1.8788 \pm 0.6055 \mathrm{microUI} / \mathrm{ml} ; \mathrm{p}<0.0001$ ). Mean FT4 level increases during metformin administration (basal FT4: $1.344 \pm 0.2514 \mathrm{ng} / \mathrm{dl}, 12$ months after metformin FT4: $1.3848 \pm$ $0.24305 \mathrm{ng} / \mathrm{dl} ; \mathrm{p}=0.001$ ) which is once again strongly significant.

Dissimilarly to the case cohort, in control group after three months, mean TSH changes from basal TSH is non-significant (basal TSH: $2.7493 \pm 1.3579 \mathrm{microUI} / \mathrm{ml}$ versus three months after TSH is $2.7518 \pm 1.3342 \mathrm{microUI} / \mathrm{ml}, \mathrm{p}=0.917$ ). Mean FT4 level changes is also non-significant (basal FT4: $1.3182 \pm 0.3080$ $\mathrm{ng} / \mathrm{dl}$, three months after FT4 is $1.3288 \pm 0.2980 \mathrm{ng} / \mathrm{dl}, \mathrm{p}=0.241$ ). After six months in control group, mean TSH changes from basal TSH is also non-significant (basal TSH: $2.7493 \pm 1.3579$ microUI/ $\mathrm{ml}$ versus six months after TSH: $2.7250 \pm 1.3266 \mathrm{microUI} / \mathrm{ml}$, $\mathrm{p}=0.358$ ).(Figure 1) At six months, mean FT4 level changes is again non-significant in the control cohort (basal FT4: 1.3182 \pm $0.3080 \mathrm{ng} / \mathrm{dl}$, six months after FT4 is $1.327 \pm 0.2894 \mathrm{ng} / \mathrm{dl}, \mathrm{p}=$ 0.324). ).(Figure 2) After 12 months in control group, mean TSH

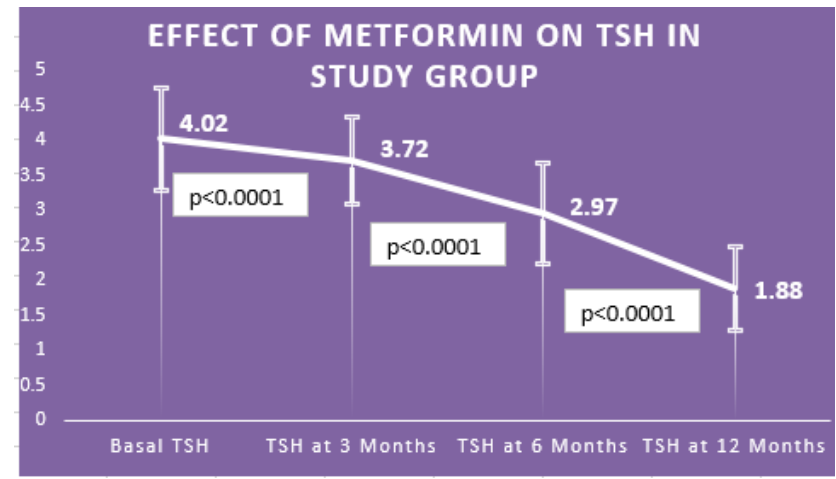

Figure 1: Effect of metformin on TSH in the study group

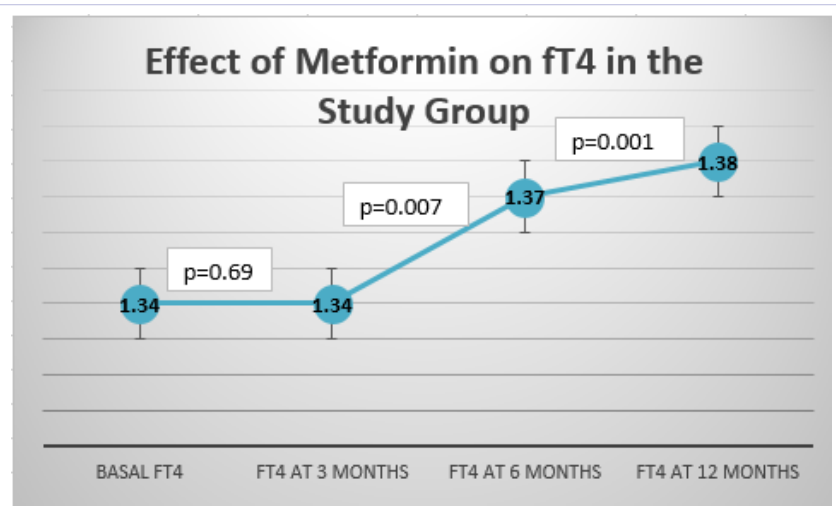

Figure 2: Effect of Metformin on FT4 in the study group 
Effect of Metformin on Serum Thyrotropin (Thyroid Stimulating Hormone) Levels in Hypothyroid Patients on Stable and Adequate Levothyroxine Doses with Diabetes or PreDiabetes

changes from basal TSH is non-significant (basal TSH:2.7493 $\pm 1.3579 \mathrm{microUI} / \mathrm{ml}$ versus. $2.7690 \pm 1.3552 \mathrm{microUI} / \mathrm{ml}, \mathrm{p}=\mathrm{s}$ 0.179. ).(Figure 1) Mean FT4 level changes is also non-significant. (basal FT4: $1.344 \pm 0.2514 \mathrm{ng} / \mathrm{dl}, 12$ months after FT4 : $1.330 \pm$ $0.2986 \mathrm{ng} / \mathrm{dl}, \mathrm{p}=0.161$ ) (Figure 2) (Tables 1, 2, 3, 4).

\section{Discussion}

Recently, researchers have observed the TSH lowering effect of metformin in patients with diabetes mellitus who are undergoing LT4 treatment and also significant reduction of TSH levels in euthyroid patients with higher baseline TSH levels independently from presence of thyroid peroxidase antibody $(T P O A b)^{4}$. Metformin acts primarily by suppressing hepatic gluconeogenesis via activation of AMPK, a prerequisite for the drug's inhibitory effect at the hepatic level. Metformin is not metabolized but is transported by the organic cation transporters (OCT), OCT1 and OCT2. Interestingly, metformin has the opposite effects on hypothalamic AMPK, inhibiting activity of the enzyme. ${ }^{6}$ Although to our knowledge, no studies are available on the regulation of AMPK sub-forms, a1 and a2, in the hypothalamus, these metformin effects on hypothalamic AMPK activity will counteract T3 effects at the hypothalamic level. ${ }^{7,8}$ AMPK

Table1: Paired samples statistics of case and control group (for TSH)

\section{Paired Samples Statistics}

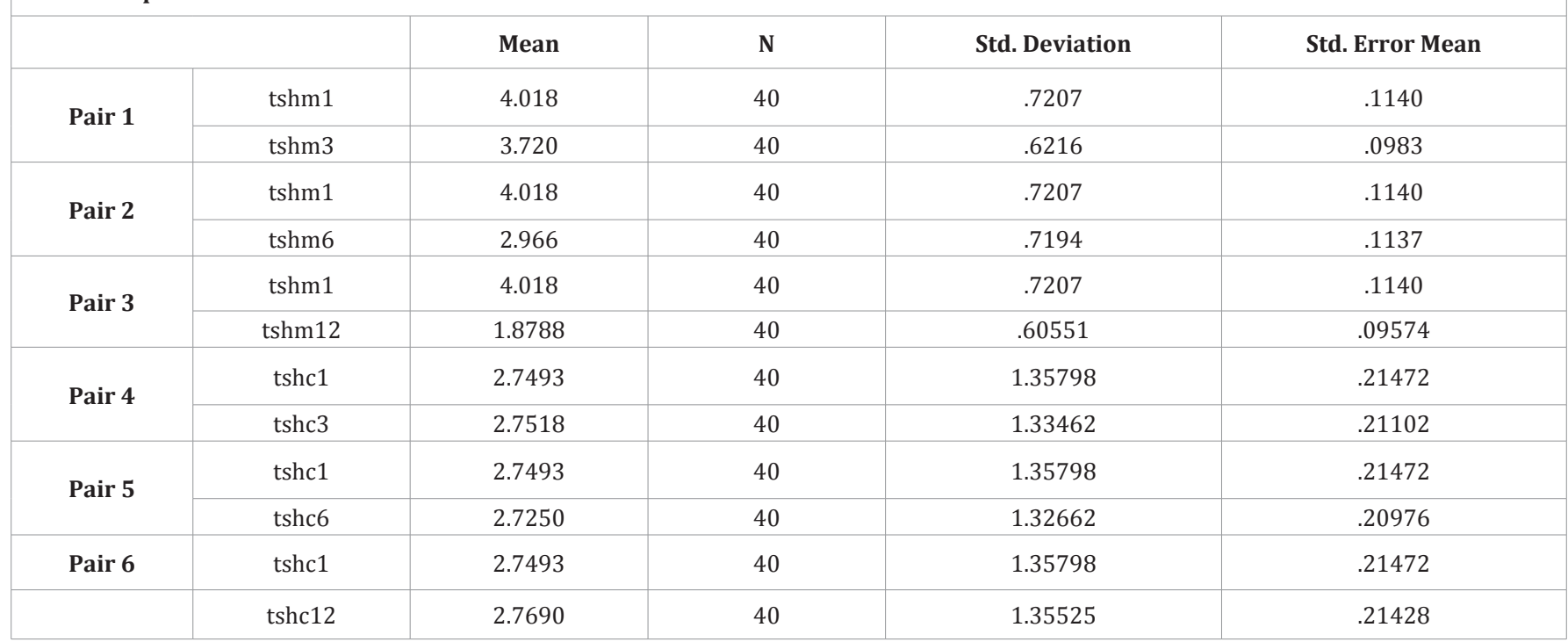

Table 2: Calculation of p value in two groups (for TSH)

Paired Samples Test

\begin{tabular}{|c|c|c|c|c|c|c|c|c|c|}
\hline & & \multicolumn{5}{|c|}{ Paired Differences } & \multirow{3}{*}{$\mathbf{t}$} & \multirow{3}{*}{ df } & \multirow{3}{*}{ Sig. (2-tailed) } \\
\hline & & \multirow{2}{*}{ Mean } & \multirow{2}{*}{$\begin{array}{c}\text { Std. } \\
\text { Deviation }\end{array}$} & \multirow{2}{*}{ Std. Error Mean } & \multicolumn{2}{|c|}{$\begin{array}{l}\text { 95\% Confidence Interval of the } \\
\text { Difference }\end{array}$} & & & \\
\hline & & & & & Lower & Upper & & & \\
\hline Pair 1 & tshm $1-$ tshm 3 & .2975 & .1806 & .0285 & .2398 & .3552 & 10.421 & 39 & $<0.0001$ \\
\hline Pair 2 & tshm $1-\operatorname{tshm} 6$ & 1.0520 & .4241 & .0671 & .9164 & 1.1876 & 15.687 & 39 & $<0.0001$ \\
\hline Pair 3 & tshm1 - tshm12 & 2.13900 & .43447 & .06870 & 2.00005 & 2.27795 & 31.137 & 39 & $<0.0001$ \\
\hline Pair 5 & tshc1 - tshc6 & .02425 & .16481 & .02606 & -.02846 & .07696 & .931 & 39 & .358 \\
\hline Pair 6 & tshc1 - tshc12 & -.01975 & .09119 & .01442 & -.04891 & .00941 & -1.370 & 39 & .179 \\
\hline
\end{tabular}


Effect of Metformin on Serum Thyrotropin (Thyroid Stimulating Hormone) Levels in Hypothyroid Patients on Stable and Adequate Levothyroxine Doses with Diabetes or PreDiabetes

Table 3: Paired samples statistics of case and control group (for FT4): Paired Samples Statistics

\begin{tabular}{|c|c|c|c|c|c|}
\hline \multicolumn{2}{|c|}{} & Mean & N & Std. Deviation & Std. Error Mean \\
\hline \multirow{2}{*}{ Pair 1 } & $\mathrm{ftm1}$ & 1.344 & 40 & .2514 & .0398 \\
\cline { 2 - 6 } & $\mathrm{ftm} 3$ & 1.3405 & 40 & .24378 & .03855 \\
\hline \multirow{2}{*}{ Pair 2 } & $\mathrm{ftm1}$ & 1.344 & 40 & .2514 & .0398 \\
\hline \multirow{2}{*}{ Pair 3 } & $\mathrm{ftm6}$ & 1.376 & 40 & .2386 & .0377 \\
\hline \multirow{2}{*}{ Pair 4 } & $\mathrm{ftm1}$ & 1.344 & 40 & .2514 & .0398 \\
\hline \multirow{2}{*}{ Pair 5 } & $\mathrm{ftm12}$ & 1.3848 & 40 & .30809 & .03843 \\
\hline \multirow{2}{*}{ Pair 6 } & $\mathrm{ftc1}$ & 1.3288 & 40 & .29803 & .04871 \\
\hline & $\mathrm{ftc3}$ & 1.3182 & 40 & .30809 & .04712 \\
\hline
\end{tabular}

Table 4: Calculation of $\mathrm{p}$ value in two groups (for FT4):

Paired Samples Test

\begin{tabular}{|c|c|c|c|c|c|c|c|c|c|}
\hline & & \multicolumn{5}{|c|}{ Paired Differences } & \multirow[b]{3}{*}{$\mathrm{t}$} & \multirow[b]{3}{*}{ df } & \multirow[b]{3}{*}{ Sig. (2-tailed) } \\
\hline & & \multirow[t]{2}{*}{ Mean } & \multirow[t]{2}{*}{ Std. Deviation } & \multirow[t]{2}{*}{ Std. Error Mean } & \multicolumn{2}{|c|}{$\begin{array}{l}\text { 95\% Confidence Interval of the } \\
\text { Difference }\end{array}$} & & & \\
\hline & & & & & Lower & Upper & & & \\
\hline Pair 1 & $\mathrm{ftm} 1-\mathrm{ftm} 3$ & .00375 & .05917 & .00936 & -.01517 & .02267 & .401 & 39 & .691 \\
\hline Pair 2 & $\mathrm{ftm} 1-\mathrm{ftm} 6$ & -.0315 & .0693 & .0110 & -.0537 & -.0093 & -2.875 & 39 & .007 \\
\hline Pair 3 & $\mathrm{ftm} 1-\mathrm{ftm} 12$ & -.04050 & .06752 & $.01068 \mathrm{v}$ & -.06209 & -.01891 & -3.794 & 39 & .001 \\
\hline Pair 4 & $\mathrm{ftc} 1-\mathrm{ftc} 3$ & -.01053 & .05587 & .00883 & -.02839 & .00734 & -1.191 & 39 & .241 \\
\hline Pair 5 & ftc 1 - ftc6 & -.00875 & .05543 & .00876 & -.02648 & .00898 & -.998 & 39 & .324 \\
\hline Pair 6 & $\mathrm{ftc} 1-\mathrm{ftc} 12$ & -.01200 & .05317 & .00841 & -.02900 & .00500 & -1.427 & 39 & .161 \\
\hline
\end{tabular}

therefore represents a direct target for dual regulation involved in the hypothalamic partitioning of energy homeostasis. In rat experiments, metformin has recently been shown to cross the blood-brain barrier and its concentrations in the hypothalamus match the levels in plasma. ${ }^{9}$ Interestingly, metformin levels in the pituitary gland are substantially increased. ${ }^{9}$ This may fit with recent findings in a still very small group of patients, suggesting that metformin suppresses pituitary TSH secretion. Metformin treatment has a TSH-lowering effect in hypothyroid patients with PCOS, both treated with L-thyroxine and untreated ${ }^{1}$. Thereby re-evaluation of thyroid function within six-twelve months after starting metformin seems necessary with concomitant hypothyroidism. Treatment with metformin is associated with a significant reduction in the serum levels of TSH in diabetic and pre diabetic patients with primary hypothyroidism receiving LT4 replacement therapy.

Several hypotheses are unable to clarify the association of metformin treatment with the decline in TSH levels even today. The possibility of metformin induced increase of thyroxine absorption from the GI tract is not likely because TSH values also declined in subjects who did not receive thyroxine as shown by other studies. It has been demonstrated that metformin crosses the blood-brain barrier and a central mechanism of TSH inhibition could thus be an attractive explanation. ${ }^{9}$ Even though it activates AMPK in the periphery, metformin suppresses AMPK activity in the hypothalamus and possibly counteracts hypothalamic T3 action on TSH secretion. ${ }^{10}$ There is also evidence that metformin treatment increases hypothalamic dopaminergic tone in association with improved insulin sensitivity. ${ }^{11}$

Other hypotheses include changes in the affinity of TH receptors, TH binding, bioavailability and metabolism, induced constitutive activation of the TSH receptor, and interference with the TSH assay. Additionally, it cannot be excluded that elevated TSH values may not necessarily reflect hypothyroidism, but could represent recovery from a nonthyroidal illness, mild resistance to $\mathrm{TH}$, or obesity, as is the case in many patients with DM receiving metformin. ${ }^{8}$

Additionally, metformin treatment resulted in a significant decrease in the nodular size (30-55\%) in insulin-resistant patients with thyroid nodules, possibly through its action on the insulin signalling pathway. ${ }^{12}$ The promising role of metformin as adjuvant therapy in the management of thyroid cancer, especially in diabetic patients is seen through various studies. Metformin has an antimitogenic and proapoptotic effect in thyroid carcinoma cell lines and augments the antiproliferative effect of chemotherapeutic agents, such as doxorubicin and cisplatin. 
Furthermore, it was found to inhibit insulin-induced growth stimulation via interference with the insulin/IGF signalling and the AMPK/mTOR pathway. ${ }^{13}$ Similarly, treatment with metformin suppressed growth and metastatic potential in medullary thyroid carcinoma cells by down regulating the mTOR pathway. ${ }^{5}$

\section{Limitations}

Since, metformin suppresses pituitary TSH secretion as described above and also in previous studies, it would be difficult to evaluate whether LT4 supplementation is adequate or not for hypothyroid patients using metformin.

\section{Conclusion}

The results of this study showed that treatment with metformin is associated with a significant reduction (at three months, six months and 12 months respectively) in the serum levels of TSH in primary hypothyroidism patients on stable and adequate levothyroxine (LT4) doses and found to have diabetes or prediabetes. TSH reduction is not associated with reciprocal changes in FT4 at three months but at six months and 12 months TSH reduction is associated with significant increase of FT4 level.

\section{Conflict of interest}

The authors declare that there is no conflict of interest regarding the publication of this article.

\section{Key Messages}

Metformin is associated with a significant reduction (at three months, six months and 12 months respectively) in the serum levels of TSH in primary hypothyroidism patients on stable and adequate levothyroxine (LT4) doses and found to have diabetes or prediabetes. TSH reduction is not associated with reciprocal changes in FT4 at three months but at six months and 12 months TSH reduction is associated with significant increase of FT4 level.

\section{References}

1. Rotondi M, Cappelli C, Magri F, Botta R, Dionisio R, Iacobello C, et al. Thyroidal Effect of Metformin Treatment in Patients With Polycystic Ovary Syndrome. Clin Endocrinol (Oxf). 2011;75(3):378-81.

2. Isidro ML, Penín MA, Nemiña R, Cordido F. Metformin reduces thyrotropin levels in obese, diabetic women with primary hypothyroidism on thyroxine replacement therapy. Endocrine. 2007;32(1):79-82.

3. Cappelli C, Rotondi M, Pirola I, Agosti B, Gandossi E, Valentini U, et al. TSH-lowering effect of metformin in type 2 diabetic patients: differences between euthyroid, untreated hypothyroid, and euthyroid on L-T4 therapy patients. Diabetes Care. 2009;32(9):1589-90.

4. Cappelli C, Rotondi M, Pirola I, Agosti B, Formenti A, Zarra E, et al. Thyreotropin levels in diabetic patients on metformin treatment. Eur J Endocrinol. 2012;167(2):261-5.

5. Klubo-Gwiezdzinska J, Jensen K, Costello J, Patel A, Hoperia V, Bauer A, et al. Metformin inhibits growth and decreases resistance to anoikis in medullary thyroid cancer cells. Endocr Relat Cancer. 2012;19(3):44756.

6. Lim CT, Kola B and Korbonits M. AMPK as a mediator of hormonal signalling. J Mol Endocrinol. 2010;44(2):87-97.

7. Bogachus LD and Turcotte, LP. Genetic downregulation of AMPK-alpha isoforms uncovers the mechanism by which metformin decreases FA uptake and oxidation in skeletal muscle cells. Am J Physiol Cell Physiol. 2010;299(6):C1549-61

8. López M1, Varela L, Vázquez MJ, Rodríguez-Cuenca S, González CR, Velagapudi VR, et al. Hypothalamic AMPK and fatty acid metabolism mediate thyroid regulation of energy balance. Nat Med. 2010;16(9):1001-8

9. Łabuzek K, Suchy D, Gabryel B, Bielecka A, Liber S, Okopień B et al Quantification of metformin by the HPLC method in brain regions, cerebrospinal fluid and plasma of rats treated with lipopolysaccharide. Pharmacol Rep. 2010;62(5):956-65.

10. Chau-Van C, Gamba M, Salvi R, Gaillard RC, Pralong FP. Metformin inhibits adenosine $5^{\prime}$-monophosphate-activated kinase activation and prevents increases in neuropeptide $\mathrm{Y}$ expression in cultured hypothalamic neurons. Endocrinology. 2007;148(2):507-11.

11. Ortega-González C, Cardoza L, Coutiño B, Hidalgo R, Arteaga-Troncoso G, Parra A. Insulin sensitizing drugs increase the endogenous dopaminergic tone in obese insulin-resistant women with polycystic ovary syndrome. J Endocrinol. 2005;184(1):233-9.

12. Rezzónico J, Rezzónico M, Pusiol E, Pitoia F, Niepomniszcze H. Metformin treatment for small benign thyroid nodules in patients with insulin resistance. Metab Syndr Relat Disord. 2011;9(1):69-75.

13. Chen G, Xu S, Renko K, Derwahl M. Metformin inhibits growth of thyroid carcinoma cells, suppresses self-renewal of derived cancer stem cells, and potentiates the effect of chemotherapeutic agents. J Clin Endocrinol Metab. 2012;97(4):E510-20. 